\title{
Research on Model Development for Freeway Safety Facilities
}

\author{
Junping Xie, ${ }^{1}$ Yongfeng $\mathrm{Ma}^{2}{ }^{2}$ and Li Yuan ${ }^{3}$ \\ ${ }^{1}$ School of Automotive and Traffic Engineering, Jiangsu University, 301 Xuefu Road, Zhenjiang, Jiangsu 212013, China \\ ${ }^{2}$ School of Transportation, Southeast University, 2 Si Pai Lou, Nanjing, Jiangsu 210096, China \\ ${ }^{3}$ College of Civil and Transportation Engineering, Hohai University, 1 Xikang Road, Nanjing, Jiangsu 210098, China
}

Correspondence should be addressed to Junping Xie; jpxie@ujs.edu.cn

Received 30 August 2014; Accepted 14 January 2015

Academic Editor: Heiner Bubb

Copyright (C) 2015 Junping Xie et al. This is an open access article distributed under the Creative Commons Attribution License, which permits unrestricted use, distribution, and reproduction in any medium, provided the original work is properly cited.

\begin{abstract}
To make freeway safety facilities function well, field survey is carried out to evaluate the maintenance quality of freeway safety facilities. In traditional models, the same weight values are assigned to the safety facilities while evaluating without considering the functional differences of different facilities. The paper develops the maintenance quality evaluation procedure and the model considering the functional differences of freeway safety facilities. In the evaluation procedure, the safety facility damage in function is the main index to get the evaluation scores for each kind of facility. The purpose of the model is to convert the evaluation scores of different safety facilities to an overall maintenance quality measure, and this result can reveal the overall facility maintenance quality of the freeway segment. In order to build the model and confirm the calculated weight of each kind of facility, Multivariable Regression and Optimized Analytic Hierarchy Process were used separately. The model was validated by comparing the proposed model evaluation results and the reorganized survey evaluation results. The coefficient of correlation $\left(R^{2}\right.$ value $)$ is 0.9048 , which shows strong correlation between the subjective evaluation and objective evaluation.
\end{abstract}

\section{Introduction}

In the past decades, freeway systems which function as the interstate freeways in the USA have been greatly developed. After the large-scale construction, the maintenance demand has increased in order to provide safe and efficient services to the travelers. In the past, many freeways in China were not well maintained due to the lack of mature maintenance technologies and theories. To relieve this defect, the government, academic institutions, and the private agencies in China have focused more on freeway quality survey and the evaluation method development.

In China, safety facilities, which refer to the ones installed along the freeway including sign, marking, guardrail, antiglare panel, separation fence, safety barrel and emergency telephone, play an important role in a freeway system. The national codes and specifications for freeway design and construction provide clear requirements for safety facilities. The main functions of the safety facilities can be described as regulating the driving behaviors, protecting travelers' lives and property when accidents happen on freeways. Similar to the other components in the freeway system, safety facilities should be maintained to obtain a certain quality level so that these functions can be fulfilled [1]. In order to maintain freeway safety facilities, field survey and evaluation are conducted regularly. Currently, in China, there is no specific safety facility maintenance quality evaluation manual or models. In 1995, the Department of Transportation published "Quality inspection and evaluation standards for highway maintenance" (JTJ 075-94) [2], in which a procedure for evaluating freeway safety facility maintenance quality was provided. The procedure was based on the judgment whether the safety facilities along freeways were well maintained. If the safety facilities were damaged and not repaired in time, certain points were reduced from the total evaluation scores. However, the procedure did not clearly identify the kinds that the safety facilities contained, and the differences of evaluating freeways between the other levels of highways were not indicated, either. Therefore, there were certain difficulties in practical applications of the procedure and standards. In 2002, another manual of the freeway maintenance quality evaluation standards (test version) was published [3]. In this 
manual, a procedure for evaluating freeway safety facilities was developed; however, the kinds of freeway safety facilities did not cover the usual ones that are installed along freeways in reality. The developed version of the 2 manuals of standards above was published in 2007 which was named as "Highway performance assessment standards" (JTG H20-2007) [4]. These standards unified the 2 separate evaluation methods on highway and freeway as the uniform one; the disadvantages in [3], however, were still included in the new standards.

It has been known that some agencies in many countries have put more efforts in highway maintenance [5-12]. Quality in highway maintenance has been the focus and discourse for several years in the USA First large scale consideration in the 1960s as part of the Maintenance Management System (MMS) concept [13]; the issue of quality in highway maintenance has since remained an active topic for more work loads and maintenance demands, limited maintenance funds, and public perceptions of maintenance departments. The need for better quality maintenance has risen significantly within the last few years in recognition for the change in focus from infrastructure design and construction to maintenance and rehabilitation. The research achievements of freeway safety facility maintenance quality evaluation are usually presented in the relative programs such as Quality Management (QM), Quality Control (QC), or Quality Assurance (QA). Although there is not a consistent procedure for evaluating safety facilities maintenance quality for freeway in the USA at present, the basic principles have been come to an agreement that there are 4 features including feature, characteristics, stand, and measures in a common evaluation procedure among the transportation agencies in most states [14]. Furthermore, the seminars are held frequently about highway maintenance, in which good experience on freeway safety facility maintenance quality evaluation can be shared by the engineers or researchers from the relative agencies.

In general, most current available procedures for assessing freeway safety facility maintenance quality are based on data collection and calculation. Each kind of safety facilities is considered as the same weight in safety and efficiency. This paper provided a procedure and model used to evaluate freeway safety facility maintenance quality based on each kind of safety facilities' service qualities considering their functional differences. The paper had the following premise: safety facility maintenance quality evaluation was based on the assumption that safety facilities were the normal ones. If some rare safety facilities were installed, the special approaches were needed to evaluate these facilities separately. Some plants planted in median can also provide the function of antiglare similar to antiglare panels and the paper only discussed the antiglare panels, and the evaluation of the plants in the median was not included.

\section{Evaluation Method}

Freeway safety facility maintenance quality evaluation is based on the data collection for each kind of facilities and the judgment on the extent the facilities can function.
To get the evaluation results of each kind of facilities, field data collection was done, in which the crucial measures were to identify and count the number of the facility damages. Complemented with the deduction score of each damage unit for safety facilities, the evaluation result of each kind of safety facilities was calculated. After that, an evaluation model was brought in by which the scores of safety facilities were turned to an overall evaluation score.

Before evaluating each kind of safety facilities on freeways, the identifications of the damages and the damage unit were defined. The evaluation result (score) was calculated by taking the deduction score from the defined full score, 100. The functions of signs are to provide regulations, warnings, and guidance information for road users. Both words and symbols are used to convey the messages. Markings on highways have important functions in providing guidance and information for the road user. Major marking types include pavement and curb markings, object markers, delineators, colored pavements, barricades, channelizing devices, and islands. In some cases, markings are used to supplement other traffic control devices such as signs, signals, and other markings. In other instances, markings are used alone to effectively convey regulations, guidance, or warnings in ways not obtainable by the use of other devices. Guardrails prevent vehicles from veering off the roadway into oncoming traffic, crashing against solid objects, or falling into a ravine. A secondary objective of guardrail is keeping the vehicle upright while it is deflected along the guardrail. Antiglare panels which are usually installed on highway median reduce the glare from oncoming car lights at night. Separation fences are usually set on both sides of highway boundaries to keep people or animals away from the driveways to avoid accidents. Traffic safety barrels are placed at some dangerous spots to absorb energy when vehicles crash against them to protect people on the vehicles. Emergency telephones are built at intervals along two sides of freeway to provide SOS call service.

\section{Deduction Score of Each Damage Unit}

To obtain the score of each kind of safety facilities, the deduction score of each damage was determined. The procedure of determination is shown in Table 1.

According to the procedure shown in Table 1, the results of deduction score of each damage unit in segment (one kilometer) are listed in Table 2.

The score of each kind of safety facility in one segment of freeway can be calculated as

$$
S_{i}=100-n D_{i}, \quad(i=1,2,3,4,5,6,7),
$$

where $S_{i}$ is the evaluation score of each safety facility for one freeway segment (one kilometer), $i=1,2,3,4,5,6,7$ represent sign, marking, guardrail, ant-glare panel, separation fence, safety barrel, and emergency telephone, separately. $D_{i}$ is the deduction score of one damage unit of each freeway facility. $n$ is the number of damages of one kind of facilities along one segment. 
TABLE 1: Procedure of the deduction score determination of each damage.

\begin{tabular}{ll}
\hline Steps & Details \\
\hline 1 & $\begin{array}{l}\text { Collect the number of damage units for each freeway } \\
\text { segment (one kilometer long) and the scores evaluated } \\
\text { subjectively by the experts. }\end{array}$ \\
\hline 2 & $\begin{array}{l}\text { Get the relationship of each safety facility between } \\
\text { number of damage and the evaluating score by linear } \\
\text { regression. }\end{array}$ \\
\hline 3 & $\begin{array}{l}\text { Calculate the slope of the equation from Step } 2 \text { of each } \\
\text { kind of safety facilities, which is the deduction score of } \\
\text { each damage unit. }\end{array}$ \\
\hline 4 & $\begin{array}{l}\text { Adjust the deduction scores according to the expert } \\
\text { opinions and get the final results. }\end{array}$ \\
\hline
\end{tabular}

TABLE 2: Deduction scores of damages of freeway safety facilities.

\begin{tabular}{lcc}
\hline Facility & Damage unit & Deduction score \\
\hline Sign & One sign & 50 \\
\hline Marking & $10 \mathrm{~m}$ length & 5 \\
\hline Guardrail & $\begin{array}{c}\text { More than } 4 \mathrm{~m}(>4 \mathrm{~m}) \\
\text { Fewer than } 4 \mathrm{~m}(\leqslant 4 \mathrm{~m})\end{array}$ & 50 \\
\hline Antiglare panel & One panel & 10 \\
\hline Separation fence & One fence & 20 \\
\hline Safety barrel & One barrel & 20 \\
\hline $\begin{array}{l}\text { Emergency } \\
\text { telephone }\end{array}$ & $\begin{array}{c}\text { One kiosk } \\
\text { (appearance damage) } \\
\text { One telephone }\end{array}$ & 30 \\
\hline & (cannot be connected) & 100
\end{tabular}

\section{Evaluation Modeling Procedure}

As discussed previously, to evaluate freeway safety facility maintenance quality, quantified indices are needed. To calculate the overall maintenance quality $(F)$ of the freeway safety facilities, the following equation was used:

$$
F=W_{1} S_{1}+W_{2} S_{2}+W_{3} S_{3}+W_{4} S_{4}+W_{5} S_{5}+W_{6} S_{6}+W_{7} S_{7}
$$

where $F$ is the index which quantifies the overall maintenance quality of the freeway safety facilities; $S_{1}, S_{2}, S_{3}, S_{4}, S_{5}, S_{6}$, and $S_{7}$ are the scores of the maintenance quality of sign, marking, guardrail, antiglare panel, separation fence, safety barrel, and emergency telephone, separately, in one kilometer freeway calculated from (1). The scores were linearly combined with weights of $W_{1}, W_{2}, W_{3}, W_{4}, W_{5}, W_{6}$, and $W_{7}$ for kinds of safety facilities.

To calibrate the model shown in (2), there were two approaches. In this paper, the Multivariable Regression analysis method and expert opinion survey based on OAHP method were used. The determination of the weights of safety facilities in the model was based on the combination of the two approaches.

4.1. Multivariable Regression Analysis Method. The first method was based on field survey. In this case, evaluating
TABLE 3: Standards of overall subjective scores for a survey panel.

\begin{tabular}{|c|c|}
\hline Scores & Rating standards \\
\hline $90 \sim 100$ & $\begin{array}{l}\text { The level of safety facility maintenance of this segment } \\
\text { is very high and the road users are completely satisfied } \\
\text { with the safety facilities. The facilities just need routine } \\
\text { maintenance. }\end{array}$ \\
\hline $80 \sim 89$ & $\begin{array}{l}\text { The level of safety facility maintenance of this segment } \\
\text { is high and the road users are satisfied with the safety } \\
\text { facilities. The facilities need routine maintenances or } \\
\text { minor repairs. }\end{array}$ \\
\hline $70 \sim 79$ & $\begin{array}{l}\text { The level of safety facility maintenance of this segment } \\
\text { is average and the road users are not very satisfied with } \\
\text { the safety facilities. The facilities need minor repairs or } \\
\text { middle-scale repairs. }\end{array}$ \\
\hline$<70$ & $\begin{array}{l}\text { The level of safety facility maintenance of this segment } \\
\text { is lower and the road users are not satisfied with the } \\
\text { safety facilities. The facilities need middle-scale repairs } \\
\text { or special repairs. }\end{array}$ \\
\hline
\end{tabular}

standards for measuring the safety facilities were needed. Table 3 shows the standards used for the overall subjective rating scores for the entire freeway safety facilities evaluation performance. To obtain the subjective ratings, a 6-people survey panel consisting of a group of roadway maintenance engineers and users was organized. The panel members considered maintenance performances of 7 kinds of safety facilities as whole for each freeway segment while rating.

The results of the freeway segments selected from panel subjective rating and the scores of 7 kinds of the safety facilities from (1) were used to calibrate the weights listed in (2) by multivariable regression analysis. The average results are shown in Table 4.

To validate the scores the surveyors rated, Kendall's $W$ (also known as Kendall's Coefficient of Concordance) was applied. Kendall's $W$ can be used for assessing agreement among different raters. Kendall's $W$ ranges from 0 (no agreement) to 1 (complete agreement). If the test statistic $W$ is 1 , then all the survey respondents have been unanimous, and each respondent has assigned the same order to the list of concerns. If $W$ is 0 , then there is no overall trend of agreement among the respondents, and their responses may be regarded as essentially random. Intermediate values of $W$ indicate a greater or lesser degree of unanimity among the various responses. Kendall's $W$ can be approximately tested by the $\chi^{2}$ distribution. In this paper, in order to test whether different field surveyors had consistent evaluation results, the 6 surveyors of the survey panel were selected to evaluate the other 10 highway segments. Results for the evaluation are presented in Table 5, and the test statistics data is presented in Table 6.

The $P$ value is $0.000<0.05$; that means the 6 surveyors of the survey panel have strong consistency in rating the overall facility maintenance performances on different freeway segments.

4.2. OAHP Method. The second approach to obtain the weights in (2) was based on the survey of the opinion of experts working in the relevant areas, such as roadway 
TABLE 4: Weights of safety facilities calculated by Multivariable Regression analysis.

\begin{tabular}{lccccccc}
\hline Kind of safety facilities & Sign & Marking & Guardrail & Antiglare panel & Separation fence & Safety barrel & Emergency telephone \\
\hline Weights & 0.30 & 0.30 & 0.20 & 0.10 & 0.03 & 0.05 & 0.02 \\
\hline
\end{tabular}

TABLE 5: Subjective scores of different surveyors for Kendall's $W$ test.

\begin{tabular}{lcccccccccc}
\hline Surveyor & Seg.1 & Seg.2 & Seg.3 & Seg.4 & Seg.5 & Seg.6 & Seg.7 & Seg.8 & Seg.9 & Seg.10 \\
\hline 1 & 100 & 87 & 60 & 92 & 83 & 98 & 89 & 75 & 100 & 100 \\
\hline 2 & 98 & 90 & 65 & 90 & 85 & 100 & 85 & 75 & 97 & 98 \\
\hline 3 & 96 & 85 & 72 & 95 & 87 & 96 & 92 & 78 & 98 & 96 \\
\hline 4 & 99 & 88 & 70 & 93 & 85 & 98 & 86 & 73 & 97 & 95 \\
\hline 5 & 100 & 84 & 68 & 90 & 85 & 98 & 88 & 77 & 98 & 99 \\
\hline 6 & 97 & 86 & 66 & 93 & 82 & 97 & 90 & 75 & 98 & 98 \\
\hline
\end{tabular}

TABLE 6: Kendall's $W$ test statistics.

\begin{tabular}{lc}
\hline$N$ & 6 \\
\hline Kendall's $W$ & 0.935 \\
\hline Chi-Square & 50.514 \\
\hline df & 9 \\
\hline Asymp. Sig. & 0.000 \\
\hline
\end{tabular}

maintenance engineers and roadway designers. More than 30 experts were independently surveyed to seek their opinions and the OAHP algorithm was used to get the weights as follows.

The Consistency Ratio (CR) is an important indicator in AHP to determine whether the consistency of pairwise comparison matrix is acceptable (usually requires $\mathrm{CR} \leq$ 0.1) [15]. It is difficult to structure a matrix, especially of high order, with satisfactory consistency for complexity of compared elements and limited ability of respondents.

A procedure for optimizing pairwise comparison matrix was used in this paper. It is presented in (3) to (6) as follows:

$$
\begin{gathered}
a_{i j}^{*}=I a_{i j}+(1-I) a_{i j}^{\prime}, \quad 1 \leq i \leq j \leq n, \\
a_{j i}^{*}=\frac{1}{a_{i j}^{*}}=\frac{1}{\left[I a_{i j}+(1-I) a_{i j}^{\prime}\right]}, \quad 1 \leq i \leq j \leq n,
\end{gathered}
$$

where $a_{i j}^{*}, a_{j i}^{*}$ are the elements of the optimized pairwise comparison matrix $A^{*}=\left[a_{i j}^{*}\right]_{n \times n} ; I$ is the credibility index; $a_{i j}$ is the element of the original pairwise comparison matrix $A ; a_{i j}^{\prime}$ is the element of the consistent pairwise comparison matrix $A^{\prime}$; it can be calculated by

$$
\left[a_{i j}^{\prime}\right]_{n \times n}=\left[\left(\frac{w_{i}}{w_{j}}\right)^{p}\right]_{n \times n}
$$

where $w_{i}, w_{j}$ are the elements of the weigh rank calculated using the original pairwise comparison matrix, $W=$ $\left[w_{1}, w_{2}, \ldots, w_{n}\right]^{T} ; p$ can be calculated by Minimum Closeness method (MC); it is shows in

$$
\begin{gathered}
\min _{p}=\min _{p} \sum_{i=1}^{n} \sum_{j=1}^{n}\left[\lg a_{i j}-\lg \left(\frac{w_{i}}{w_{j}}\right)^{p}\right]^{2}, \\
p=\frac{\sum_{i=1}^{n} \sum_{j=1}^{n} \lg a_{i j} \lg \left(w_{i} / w_{j}\right)}{\sum_{i=1}^{n} \sum_{j=1}^{n}\left(\lg \left(w_{i} / w_{j}\right)\right)^{2}},
\end{gathered}
$$

where $a_{i j}$ is the same as (3); $w_{i}, w_{j}$ are the same as (5).

The credibility index $I$ represents the proportion between original pairwise comparison matrix $A$ and consistent pairwise comparison matrix $A^{\prime}$ in optimized pairwise comparison matrix $A^{*}$. If $\mathrm{CR} \leq 0.1$ in $A^{*}$, the larger $I$ is, the greater percentage of $A$ is included in $A^{*}$ and that means the weights calculated from $A^{*}$ are more credible. A trial method was used to determine the appropriate value of $I$ by Matlab and if the largest value of $I$ was more than 0.6 , the weight results were considered acceptable.

The weights of different safety facilities that resulted from the OAHP analysis are shown in Table 7.

4.3. Final Model. The final weights were determined by taking average of the results of Multivariable Regression analysis and expert opinion survey based on OAHP. The final results are shown in Table 8 .

Equation (2) can be illustrated as (7) according to the results in Table 8:

$$
\begin{aligned}
F= & 0.27 S_{1}+0.27 S_{2}+0.2 S_{3}+0.12 S_{4} \\
& +0.05 S_{5}+0.06 S_{6}+0.03 S_{7},
\end{aligned}
$$

where the definitions of $F$ and $S$ are the same as (2). Theoretically, (7) is better than the models only from one single method.

\section{Field Survey Form}

To effectively collect field data for freeway safety facility evaluation, a comprehensive survey form was prepared. Table 9 shows the survey form. The form provides the deduction 
TABLE 7: Weights of safety facilities resulting from OAHP analysis.

\begin{tabular}{lccccccc}
\hline Kind of safety facilities & Sign & Marking & Guardrail & Antiglare panel & Separation fence & Safety barrel & Emergency telephone \\
\hline Weights & 0.24 & 0.24 & 0.20 & 0.13 & 0.07 & 0.08 & 0.04 \\
\hline
\end{tabular}

TABLE 8: Final results of weights of safety facilities.

\begin{tabular}{lccccccc}
\hline Kind of safety facilities & Sign & Marking & Guardrail & Antiglare panel & Separation fence & Safety barrel & Emergency telephone \\
\hline Weights & 0.27 & 0.27 & 0.20 & 0.12 & 0.05 & 0.06 & 0.03 \\
\hline
\end{tabular}

TABLE 9: Survey form for freeway safety facility maintenance performance evaluation.

\begin{tabular}{llc}
\hline Freeway code: & Origin landmark: & Date: \\
\hline Facility & Damage description & $\begin{array}{l}\text { Deduction score of } \\
\text { one damage unit }\end{array}$ \\
\hline Marking & $10 \mathrm{~m}$ damage length as one damage unit and counted as one if less & $\begin{array}{l}\text { Number of } \\
\text { damages }\end{array}$ \\
\hline Sign & One sign damage as one damage unit & 50 \\
\hline Guardrail & Damage length less than $4 \mathrm{~m}$ (including $4 \mathrm{~m}$ ) as one damage unit & 30 \\
\hline Antiglare panel & Damage length more than 4 m as one damage unit & 50 \\
\hline Separation fence & One fence damage as one damage unit & 10 \\
\hline Safety barrel & One facility (including protection net or Crash Cushion or Safety & 20 \\
\hline $\begin{array}{l}\text { Emergency } \\
\text { telephone }\end{array}$ & One kiosk appearance damage as one damage unit & 20 \\
\hline
\end{tabular}

scores for each kind of damage unit and the blanks to count number of damages in one freeway segment (one kilometer long for one segment). It is easy to get the evaluation result using the form and (7).

\section{Model Validation}

The validation procedure was based on the comparison between the evaluation from the final model shown in (7) and the evaluation performed by a reorganized survey crew. In this validation, 16 freeway test segments were used. The survey crew was divided into two teams; one team focused on the subjective evaluation of overall safety facility maintenance quality and the other one worked on collecting the field data using the survey form (see Table 9) to calculate the results by the final model.

Figure 1 presents the validation results. It shows strong correlation between the model evaluation results and the subjective evaluation results. The coefficient of correlation ( $R^{2}$ value) is larger than 0.9 , indicating that the final model shown in (7) is valid and reasonable.

\section{Conclusions}

Freeway safety facilities, which usually consist of road sign, marking, guardrail, antiglare panel, separation fence, safety barrel, and emergency telephone, play an important role in a freeway system to ensure the safety of driving.

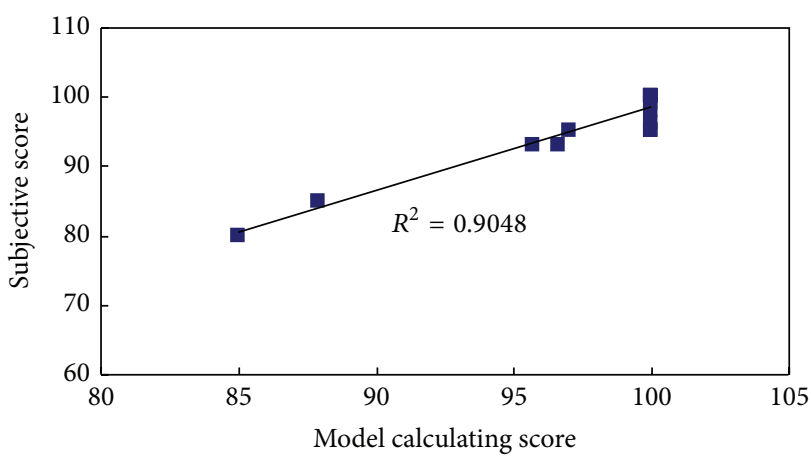

FIGURE 1: Comparison between subjective scores and final model calculating scores.

A developed model for evaluating maintenance performances of freeway safety facilities by consideration of the functional differences of different kinds of safety facilities was constructed using Multivariable Regression and the Optimized Analytic Hierarchy Process (OAHP) simultaneously. Multivariable Regression concentrated on evaluation score of each kind of safety facility collected by field surveyors and subjective rating of overall facility maintenance quality evaluation provided by a panel. 2 data sets were used for regression analysis to get the one set of weights. On the other hand, the OAHP was conducted based on expert opinions and the other set of weights was provided. The model was developed by averaging the corresponding weights in the 2 
sets of the calculated weights. Furthermore, the evaluating procedure including survey form was also presented in the paper.

According to the evaluating procedure developed, highway engineers are able to more conveniently and objectively quantify maintenance performances of the safety facilities.

\section{Conflict of Interests}

The authors declare that there is no conflict of interests regarding the publication of this paper.

\section{Acknowledgments}

The authors would like to thank the Highway Maintenance Performance Evaluation in Jiangsu Province project and some further work was carried on by the support of the National Natural Science Foundation of China (nos. 51208232, 51208100 and 51308192) and the Scientific Research Foundation for Advanced Talents of Jiangsu University (no. 13JDG074).

\section{References}

[1] China Communications Press, "Technical specifications of maintenance for highway," Tech. Rep. JTG H10-2009, Department of Transportation, China Communications Press, 2009.

[2] "National standards for highway maintenance and quality evaluation," JTJ 075-94, Department of Transportation, China Communications Press, 1995.

[3] (Test Version), National Standards for Freeway Maintenance and Quality Evaluation, Department of Transportation, China Communications Press, 2002.

[4] Research Institute of Highway Ministry of Transport and China Communications Press, "Highway performance assessment standards," Tech. Rep. JTG H20-2007, Research Institute of Highway Ministry of Transport, China Communications Press, 2007.

[5] S. Zhu, "Traffic safety maintenance evaluation of national and provincial arterial highway facilities in China," Applied Mechanics and Materials, vol. 209-211, pp. 952-958, 2012.

[6] S. Y. Jeong, J. U. Kim, and S. S. Yang, "A study on the development of highway facility information library system," in Proceedings of the 25th International Symposium on Automation and Robotics in Construction (ISARC '08), pp. 476-482, June 2008.

[7] TRB, "Performance-based highway maintenance and operations management," NCHRP Synthesis 426, 2012.

[8] K. Madelin, "Highway maintenance management in Shropshire," Proceedings of the Institution of Civil Engineers: Transport, vol. 105, no. 2, pp. 97-103, 1994.

[9] J. Lu and Q. Xiang, Highway Safety Facility Maintenance Performance Evaluation and Forecasting Models, Jiang Su Province Department of Transportation, Transportation College, Southeast University, Nanjing, China, 2007.

[10] T. Lam and K. Gale, "Framework procurement for highways maintenance in the UK: can it offer value for money for publicsector clients?" Structure and Infrastructure Engineering, vol. 11, no. 5, pp. 695-706, 2014.

[11] D.-Y. Lee and M.-J. Lee, "A study of the asset valuation method for efficient road facility maintenance," Journal of Asian
Architecture and Building Engineering, vol. 13, no. 2, pp. 279286, 2014.

[12] J. M. de la Garza and J. L. Arcella, "Current performance-based maintenance methods to improve Virginia highways," Transportation Research Record, no. 2361, pp. 35-43, 2013.

[13] American Association of State Highway and Transportation Officials (AASHTO), Guidelines for Maintenance Management System, American Association of State Highway and Transportation Officials, Washington, DC, USA, 2005.

[14] J. Lu, L. Yuan, and Q. Ge, "Development of a model for freeway green landscape evaluation," Transportation Research Record, vol. 2025, pp. 63-71, 2007.

[15] T. L. Saaty and L. G. Vargas, Models, Methods, Concepts \& Applications of the Analytic Hierarchy Process, Kluwer Academic Publishers, New York, NY, USA, 2001. 


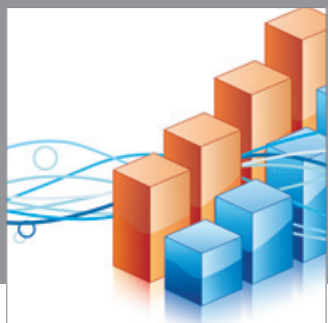

Advances in

Operations Research

mansans

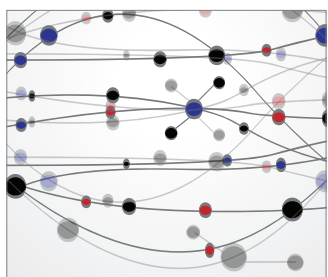

The Scientific World Journal
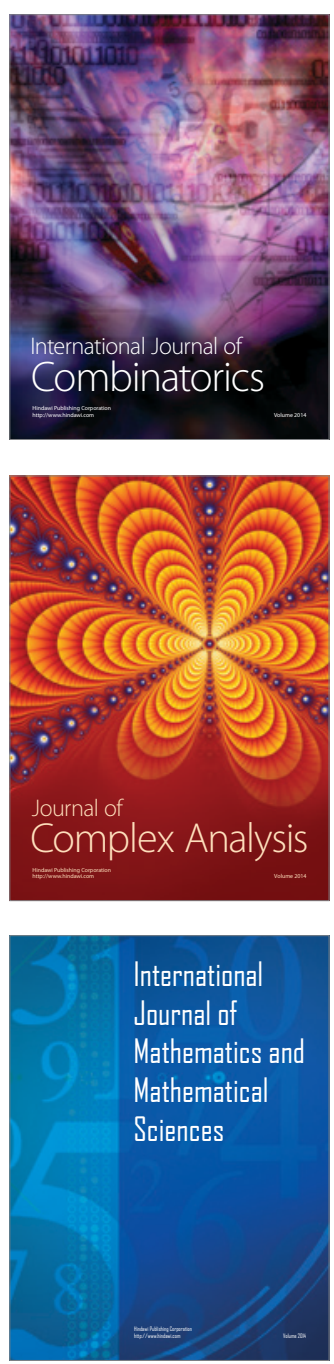
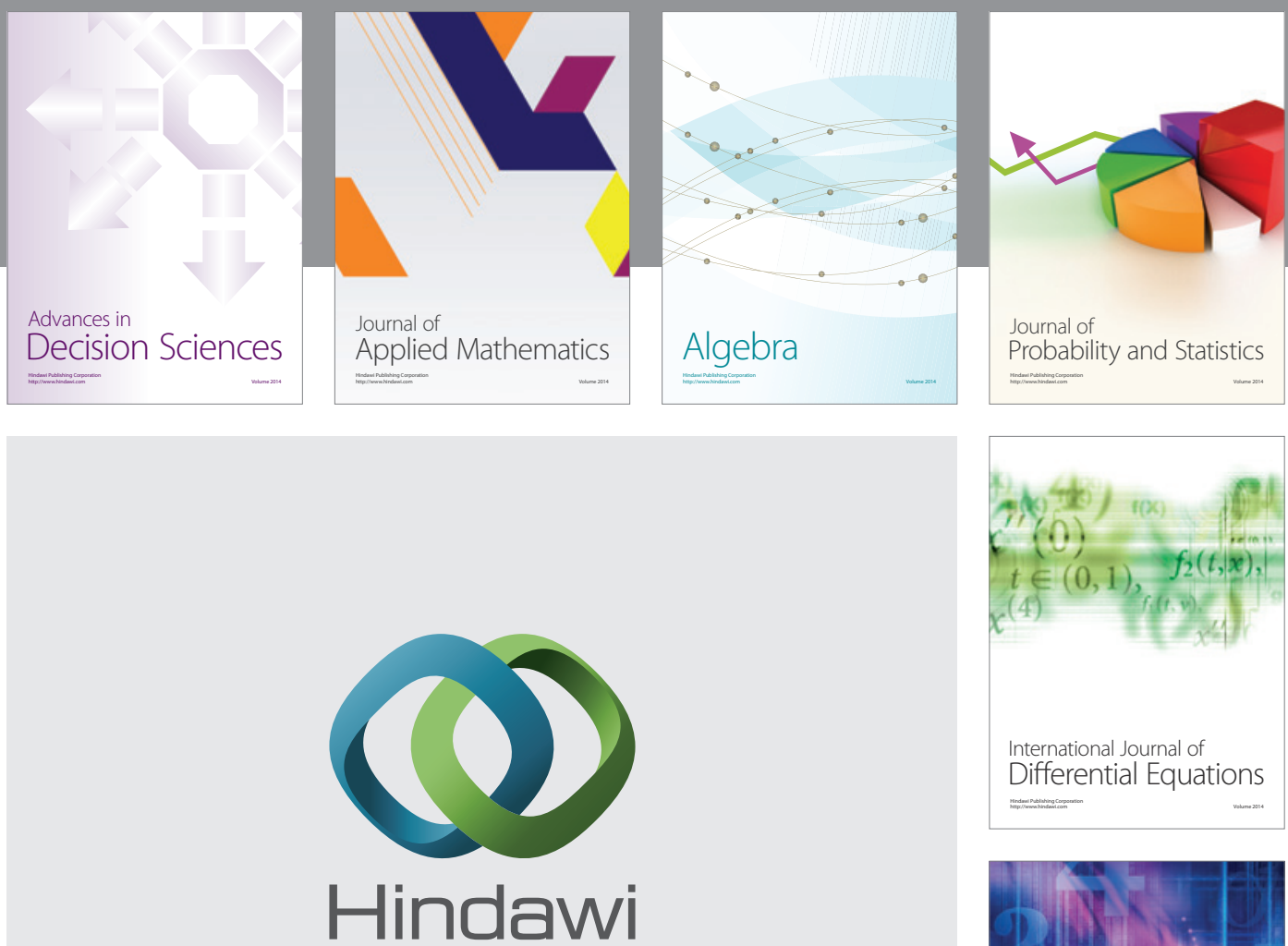

Submit your manuscripts at http://www.hindawi.com
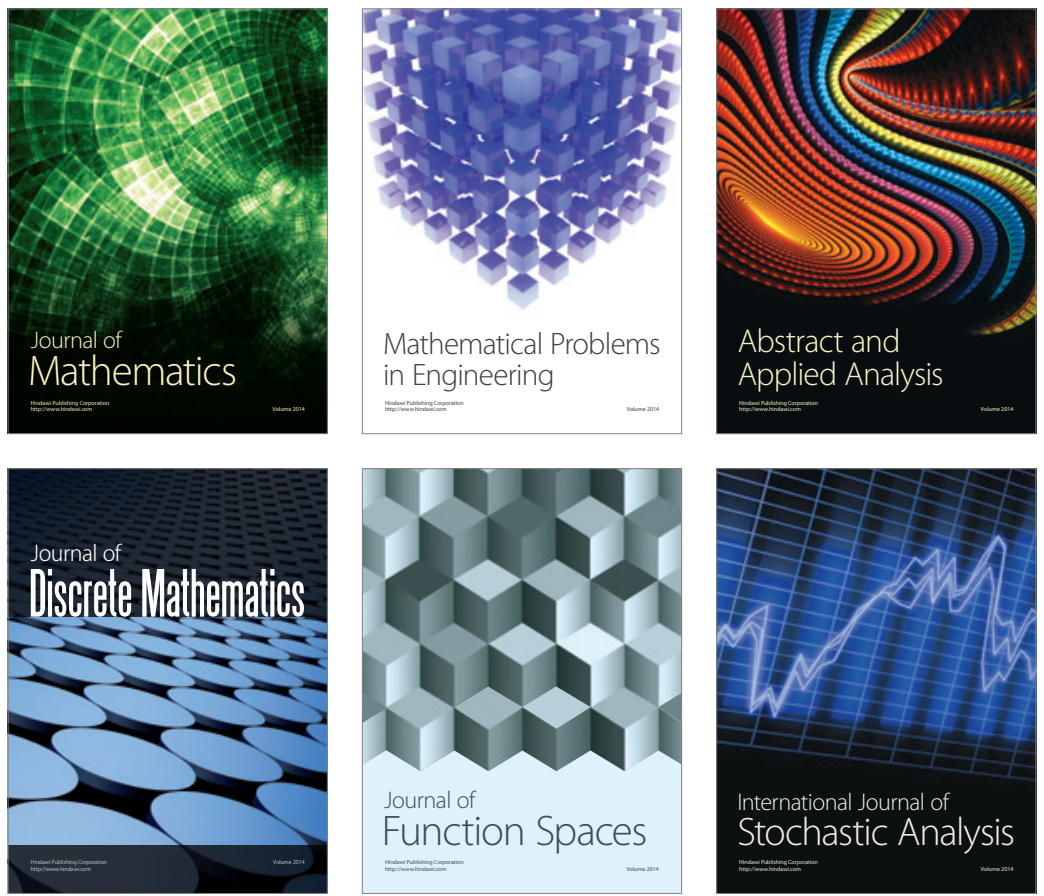

Journal of

Function Spaces

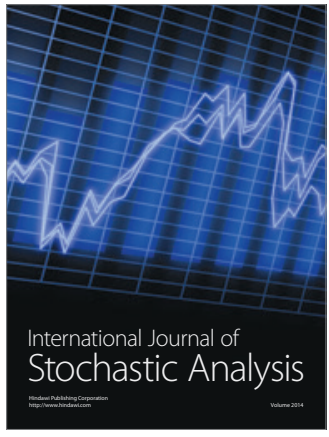

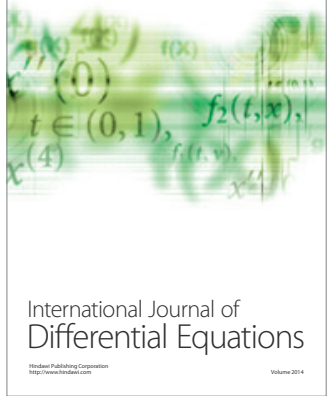
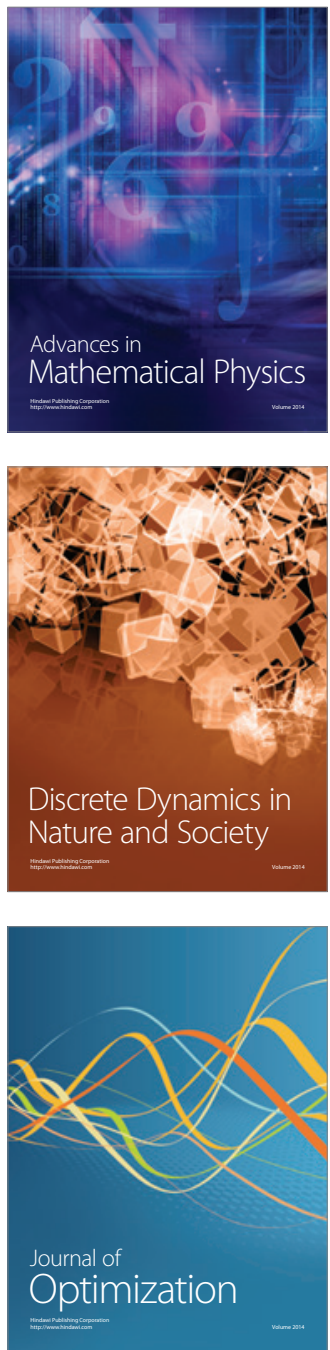